\title{
A STUDY OF BRACKISH WATER MEMBRANE WITH ULTRAFILTRATION PRETREATMENT IN INDONESIA'S COASTAL AREA
}

\author{
Elis Hastuti ${ }^{1 *}$, Made Widiadnyana Wardiha ${ }^{2}$ \\ ${ }^{1}$ Research Institute for Human Settlements, Ministry of Public Works, Indonesia \\ ${ }^{2}$ Denpasar Experimental Station for Traditional Housing Technology Development, Ministry of Public Works, \\ Indonesia
}

Received 26 March 2011; received in Revised form 29 January 2012 accepted 30 March 2012

\begin{abstract}
Water pollution and sea water intrusion to water sources in coastal areas result lack of provision safe drinking water by the drinking water regional company or coastal community. The existing water treatment plant that operated on brackish surface water or groundwater feed requires improving process. Membrane process could be a choice to treat the quality of brackish water to the level of potable water that designed to lower cost with high stabile flux and longer lifetime. This research focus on application of pilot plant of brackish water treatment using Ultrafiltration (UF) membrane-air lift system as pretreatment of Reverse Osmosis (RO) membrane-low pressure. Brackish water sources contain high colloidal and suspended solids that can cause fouling load of RO membranes and impair its performance. UF pretreatment operation tested by addition of compressed air into the feed (air lift system), resulted stable flux, reduces membrane fouling and low feed pressure. A flux of RO with UF pretreatment can produce drinking water of $30-61 \mathrm{~L} / \mathrm{m}^{2} \cdot$ hour. It was observed, the good quality of RO permeate resulted by using a pretreatment of UF-PS (Polysulfone-UF) with total dissolved solid rejection about $96-98 \%$ and color rejection about $99-100 \%$ at 5 or 8 bars of operation pressure. This paper concludes that performance of membrane technology with UF-air lift system pretreatment and RO membrane-low pressure could be accepted as condition of brackish water source in Indonesia coastal areas in producing drinking water.
\end{abstract}

Keywords: Brackish water; UF; pretreatment; air lift system; RO

(c) 2012 Journal of Urban and Environmental Engineering (JUEE). All rights reserved.

\footnotetext{
* Correspondence to: Elis Hastuti, Tel.: +62 81320274107 Ext 27; Fax: +62 227798393
}

E-mail: elishastuti@yahoo.com 


\section{INTRODUCTION}

The Indonesia government have the authority and responsibility to provide access to safe drinking water as Millennium Development Goals (MDGs) that have to reduce by half the proportion of people without sustainable access to safe drinking water and basic sanitation by 2015 (Ministry of Public Works, 2010). The provision of proper water infrastructure in coastal area aims to implement the government regulation no. $16 / 2005$ which mentions that all the water produced by water supply system is potable water. The availability of fresh water depends on the quality of groundwater and strongly influenced by rainfall, sea level rise and intensity of coastal development activities. Some studies showed the position of the seawater interface in Indonesia indicated a rise in all regions in a range of approximately $10 \mathrm{~mm}$ per year to $20 \mathrm{~mm}$ per year (Rahman, 2010). This impact, accelerated by high groundwater exploitation and uncontrolled development in coastal cities, results in increasing the widespread inundation, coastal erosion, seawater intrusion, what changes the quality of surface and groundwater.

The major challenge of water infrastructure in Indonesia coastal areas is surface water and groundwater for drinking water sources as categorized as brackish water with Total Dissolved Solid (TDS) is around $1200-5000 \mathrm{mg} / \mathrm{L}$, including some coastal areas in Java Island. Monitoring of water quality in the river and villager's wells in the City of Indramayu, West Java, showed that they have been intruded by seawater with TDS of $1680-2400 \mathrm{mg} / \mathrm{L}$ and chloride content of about $380-635 \mathrm{mg} / \mathrm{L}$. The raw water of drinking water regional company (PDAM) at Kronjo Sub-district, Tangerang City, West Java, has also intruded by sea water resulted surface water with TDS value more than $2000 \mathrm{mg} / \mathrm{L}$.

Surface water and groundwater that have been intruded by sea water and contaminated by waste, has led to the performance of the existing conventional water treatment unit is not able to meet a drinking water quality and high cost of operation because of high chloride salt content and other pollutants in the raw water. Therefore, advanced treatment is required to produce drinking water quality. In this pilot study, suitability membrane process to treat raw water source or brackish water was done by applying Ultrafiltration (UF) membrane as pretreatment of Reverse Osmosis (RO) membrane. The system employs a UF membrane completed air lift system to separate of colloidal and suspended solid in brackish water, therefore, reducing the concentration of fouling constituent in UF or RO membranes.

\section{Membrane technology for brackish water treatment}

Water is categorized fresh water has a TDS of less than $1000 \mathrm{mg} / \mathrm{L}$, TDS of brackish water is around 1000-5000 $\mathrm{mg} / \mathrm{L}$, TDS of very -brackish water is around 5000 $15,000 \mathrm{mg} / \mathrm{L}$, TDS of saline is around 15 000-30000 $\mathrm{mg} / \mathrm{L}$ and sea water has TDS more than 30 000-40 000 $\mathrm{mg} / \mathrm{L}$ (Cheremisinoff, 2002). The content of soluble salts in the water which occupies the largest amount on this earth, require special processing to obtain potable water consumption. Conventional treatment, e.g. by coagulation flocculation and sand filtration, have shown their limitation; therefore, advanced treatment processes are required.

The salt content and colloidal or suspended solids can be removed with membrane process. Ultrafiltration (UF) membrane start to recognized as the best pretreatment before Reverse Osmosis (RO) membrane because it removes, in only one physical filtration stage, all the suspended solids and biological materials of the seawater (Lorain et al., 2007). According to Pearce, 2008 , membrane filtration is accepted as the best pretreatment alternative for some feed sources and in some markets, whereas it is considered expensive or unnecessary in other cases. For example, membranes are accepted in all markets for wastewater pre-treatment, whilst for surface water, acceptance varies with location.

In the UF membrane as pretreatment, the liquid to be filtered is forced into the assemblage and dilute permeate passes perpendicularly through the membrane while concentrate passes out the end of the media (Cheremisinoff, 2002). Pretreatment chemicals used in a clarifier such as alum, ferric chloride, or cationic polyelectrolyte can also cause colloidal fouling if not removed in the clarifier or through proper media filtration. Appropriate pretreatment can be selected based on the lab analysis of the wastewater constituents, but a treatability study proves the suitability of the chosen pretreatment options. In Table 1, it shows pretreatment options before membrane process (Alley, 2006). To provide the best performance for UF, pretreatment can be completed by the air lift system. It uses the air lift effect to drive liquid flow tangentially across the membrane surface whilst simultaneously making use of the enhancing effect of gas bubbles on membrane performance (Cui et al., 1997). The air flow rate is chosen to avoid any suspended solids settling in the membrane module (Heran et al., 2006).

Reverse osmosis (RO) membrane process is by applying pressure to the saline water, the flow process through the membrane can be reversed. When the applied pressure on the salt solution is greater than the 
Table 1. Pretreatment selection

\begin{tabular}{|c|c|c|}
\hline Quality & $\begin{array}{l}\text { Membrane } \\
\text { Process }\end{array}$ & Pretreatment \\
\hline $\begin{array}{l}\text { Total suspended } \\
\text { solid }\end{array}$ & UF, NF, RO & $\begin{array}{l}\text { Gravity settling, media } \\
\text { filtration, cartridge } \\
\text { filtration }\end{array}$ \\
\hline Organic & $\mathrm{NF}, \mathrm{RO}$ & $\begin{array}{l}\text { Activated carbon } \\
\text { adsorption }\end{array}$ \\
\hline $\begin{array}{c}\text { Scalant (Ca, } \\
\text { Mg, metal } \\
\text { hydroxide, } \\
\text { metal oxide, etc) }\end{array}$ & $\begin{array}{l}\text { MF, UF, NF, } \\
\text { RO }\end{array}$ & $\begin{array}{l}\text { Precipitation, filtration, } \\
\text { chemical addition, ion } \\
\text { exchange }\end{array}$ \\
\hline $\begin{array}{l}\text { Fats, Oil and } \\
\text { Grease }\end{array}$ & $\mathrm{NF}, \mathrm{RO}$ & $\begin{array}{l}\text { Gravity separation, } \\
\text { emulsion breaking, UF }\end{array}$ \\
\hline High/ low pH & $\begin{array}{l}\text { MF, UF, NF, } \\
\text { RO }\end{array}$ & $\mathrm{pH}$ adjustment \\
\hline Organic matter & $\begin{array}{l}\text { MF, UF, NF, } \\
\text { RO }\end{array}$ & $\begin{array}{l}\text { Gravity separation, } \\
\text { filtration, chlorination }\end{array}$ \\
\hline
\end{tabular}

, $2007 . \mathrm{MF}$ : Microfiltration, UF: Ultrafiltration,

NF : Nanofiltration, RO : Reverse Osmosis

osmotic pressure, fresh water diffuses in the opposite direction through the membrane and pure solvent is extracted from the mixed solution (Cheremisinoff, 2002). The amount of energy required for osmotic separation is directly related to the salinity of the solution. Colloidal fouling of reverse osmosis elements can seriously impair performance by lowering productivity and salt rejection. Application of UF/MF membrane pretreatment ensures that significantly higher fluxes are obtained from the RO, with much less fouling, reduced chemical usage, and better on-stream time (Pearce, 2008).

Another important aspect in the design of a membrane filtration system is the membrane material. The ideal membrane material has the following qualities: high selectivity, high permeability, mechanical stability, temperature stability and chemical resistance. Membrane materials may be classed in three broad categories: modified natural products, synthetic products and inorganic products (Rautenbach and Albrecht, 1989). The modified natural product membranes consist of such materials as cellulose acetate, cellulose acetobutyrate, and cellulose regenerate. The synthetic product membranes consist of such materials as aromatic polyamide, polysulfone, polyethylene, polypropylene, and polyfuran. Synthetic product membranes are very versatile and may have excellent temperature stability and chemical resistance (Alley, 2007).

\section{METHOD}

There are many options for water treatment to achieve safe access drinking water in coastal areas which have shortage of freshwater and increased sea water intrusion to existing fresh water sources. One of options, such membrane applications, is required to provide the best performance for water treatment process. Our study aims to study performance of membrane system for treating brackish water, which consists of UF and RO membranes. This study is from June to November 2008. According to membrane specifications, UF membrane unit has a capacity of $500-1000 \mathrm{~L} / \mathrm{h}$ and RO membrane unit has a permeate production capacity of $300 \mathrm{~L} / \mathrm{h}$ (polyamide, BW30-4040, FILMTEC). Brackish water was pumped from water source directly to UF module followed by carbon filtration and cartridge filtration. This pretreatment of RO applied to remove dissolved, colloidal and suspended solid.

One of pilot plant experiments which was conducted in Indramayu city was done with modification of air injection system in UF filtration process and also in UF backwash process. The applied pressure for RO process is low, thus less energy is required to produce drinking water. The UF membrane performance in treating brackish water with different material membranes was analyzed in the aim to know stable flux, permeate quality and long term performance of membrane elements.

The membrane operation is intended to study UF membrane operation with two types of synthetic membrane material and air lift operation system. Synthetic product of UF membranes were tested consist of polysulfone and polypropylene materials which may have temperature stability and chemical resistance (Alley, 2007). The scheme of membrane system with air injection application in the UF membrane feed shown at Fig. 1. Two hollow fiber UF membranes were tested which made of polysulfone $\left(0.1 \mu \mathrm{m}\right.$ pore size, $0.9 \mathrm{~m}^{2}$ filtration area, China) and polypropylene $(0.1 \mu \mathrm{m}$ pore size, $0.9 \mathrm{~m}^{2}$ filtration area, Indonesia). Both of the membrane materials can work on a large $\mathrm{pH}$ range of 2 13 , but has different pore size so that they will have different pressure range.

Air was supplied to feed UF to prevent membrane fouling. The UF membrane was backwashed with permeate water when the flux decreased more than $30 \%$. Backwash with chemical was carried out when the flux decreased and the membrane cannot return to the initial flux with clean water backwash.

The analyzed parameter for the raw water and permeate water were turbidity, DHL, $\mathrm{pH}$, TDS. The methods for water quality analysis had been used Indonesian National Standard (SNI). Water quality was compared with Indonesia's Healthy Ministry standard no. 492/MENKES/PER/IV/2010 for drinking water requirements. To analyze membrane performance, monitoring of flux and pressure at the influent flow, permeate and concentrate quality were done during operation of membranes. 


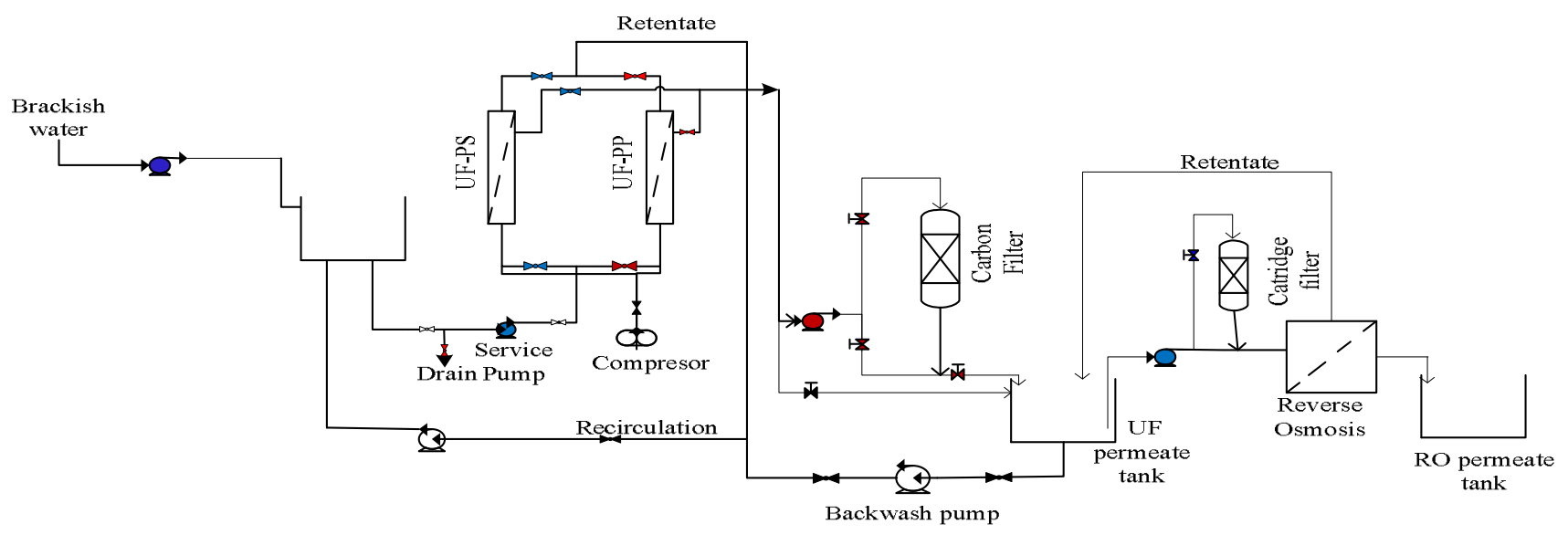

Fig. 1 UF and RO membrane module for brackish water treatment.

\section{RESULT AND DISCUSSION}

The studies of water supply in some coastal cities showed the existing water treatment plants could not be able to handle surface water quality with high salt content, which comes from seawater intrusion or inundation. The existing raw water source has also been contaminated by wastewater and solid waste from housing area. Increasing groundwater exploitation, waste contamination and seawater intrusion had caused water supply problem in Tangerang city, Coastal area in West Java and require significant changes for water treatment plant. In dry season, raw surface water source was observed the salinity and organic content were high. Result of surface water monitoring as raw water of WTP Kronjo, Tangerang city showed water with high TDS and high organic contamination with BOD more than 20 $\mathrm{mg} / \mathrm{L}$ and fecal coliform about $600 \mathrm{MPN}$ per $100 \mathrm{ml}$.

Increased coastal erosion, inundation and sea water intrusion also happened in Indramayu City, West Java, which has $114.1 \mathrm{~km}$ of coastline. It is predicted that Indramayu coasts are very vulnerable toward seawater inundation with sea level rise (SLR) tend is around 3.8 $\mathrm{mm} /$ year (Rudiastuti et al., 2010). Results of monitoring of surface and groundwater quality show TDS of about $1680-2400 \mathrm{mg} / \mathrm{L}$ and chloride content of about 380-635 $\mathrm{mg} / \mathrm{L}$, besides that the water contains high colloids and suspended solids from surface run off and uncontrolled wastewater discharge. The pictures in the Fig. 2 show one of ten villages in Tangerang and Indramayu which facing problem of fresh water shortage caused by seawater intrusion. Their existing water treatment plant consists of conventional process which has corroded on some components. Thus, technically adaptation to safe water supply is required, which could consider membrane technology application to produce safe drinking water. Szép et al. (2009) stated membrane separation processes are important and the life cycle costs of filtration are comparable with conventional treatments though their capital costs are higher. The (a)

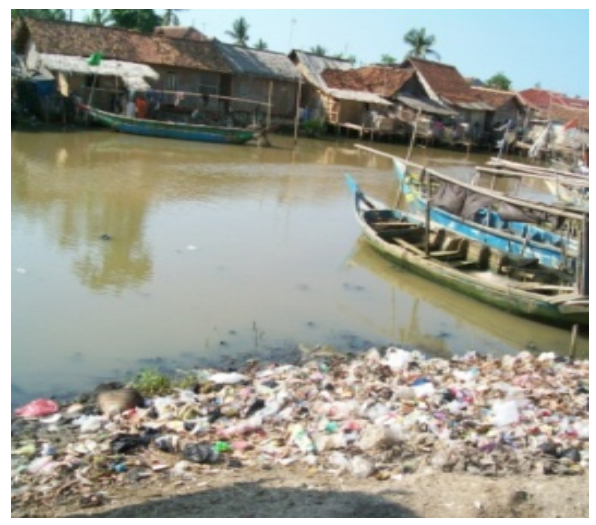

(b)

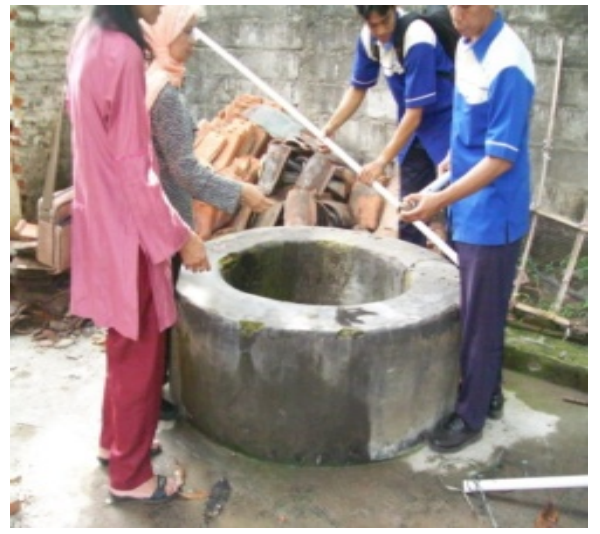

(c)

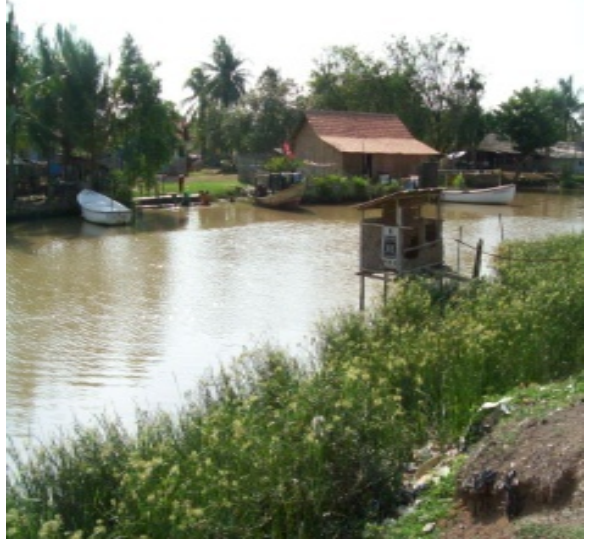

Fig.2 Surface water and groundwater intruded by seawater and domestic waste in some coastal areas: (a) illegal disposal of solid waste, (b) seawater intrusion, and (c) direct discharge of human waste. 
footprint of MF/UF could be less than conventional filters with less consumption of chemicals (Vedavyasan, 2007; Szép et al., 2009).

\section{Application Membrane Technology: a Case study}

The pilot application of membrane technology is composed by two primary membranes, the UF membrane and RO membrane. The UF membrane could be a proper pretreatment selection for RO membrane and it had been designed to support high hydraulics performance and prevent membrane fouling. A case study in Indramayu city, our pilot plant study had been done with brackish water feed with varied quality at observation time every hour of daily monitoring, as shown at Fig. 3.

The raw water before entering UF membrane passed to the wired screen to remove coarse material. Applying continuous sampling of raw water, it was observed the quality had a range of variation, brackish water usually has EC value around $2500-3250 \mu \mathrm{S} / \mathrm{cm}$ and turbidity of about 56-179 NTU. Chloride content in the raw water was more than drinking water standard $(250 \mathrm{mg} / \mathrm{L})$ that need to be removed for water consumption. High color of raw water source also was observed during membrane operation, which caused by organic material or micro nutrient from waste pollution in the water source. Turbidity of raw water should be controlled periodically in order to process UF pretreatment in an effective way and to prevent the RO membrane fouling. Strong variations of raw water quality in this case still can be pretreated by UF membrane.

\section{UF pretreatment performance}

UF membrane module is operated in cross flow mode with periodic backwash. The performance of UF membrane processes in brackish water pretreatment can be enhanced by turbulence of membrane surface through air lift by air injection in the feed for prevention of fouling or scale on the membrane. Two UF membranes were tested as parallel operation as RO pretreatment, followed by carbon and cartridge fiber filtration. The result of average flux observation of UFPS and UF-PP operation with and without air lift are given at Figs 4-5. UF membrane operated in cross flow at a pressure about 1 and 2 bars, operation of UF with air lift system supports achieving resulting more stable membrane flux. Flux measurements were taken after UF membrane in steady operation or membrane had been backwash with clean water for two-three times. It was observed that time duration of the filtration cycle with air lift system both two types of UF membranes is approximately 8 hours, but filtration cycle

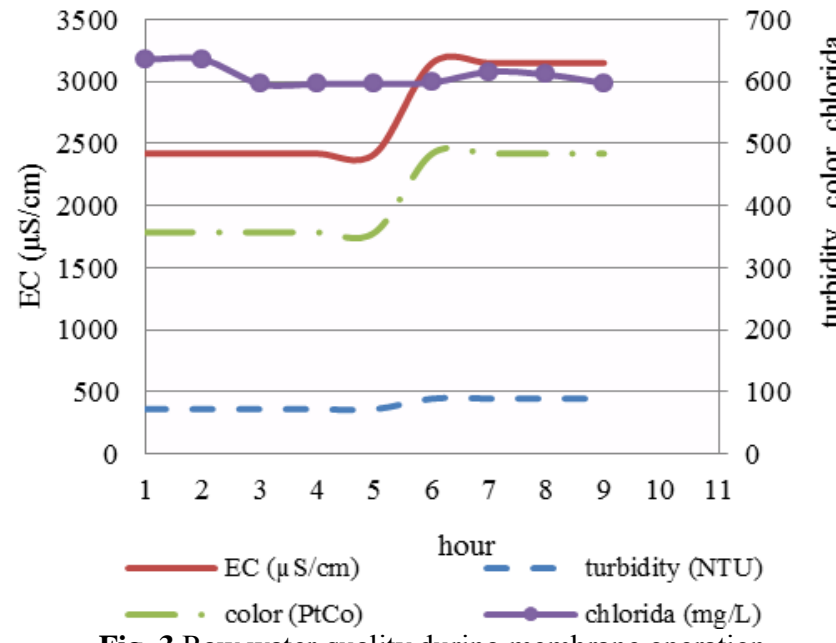

Fig. 3 Raw water quality during membrane operation.

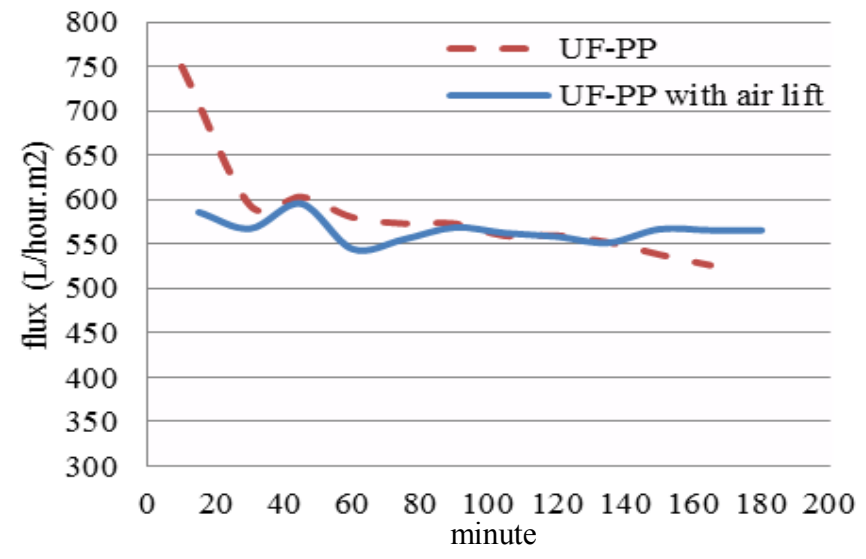

Fig. 4 Membrane flux of UF-PP as RO membrane pretreatment.

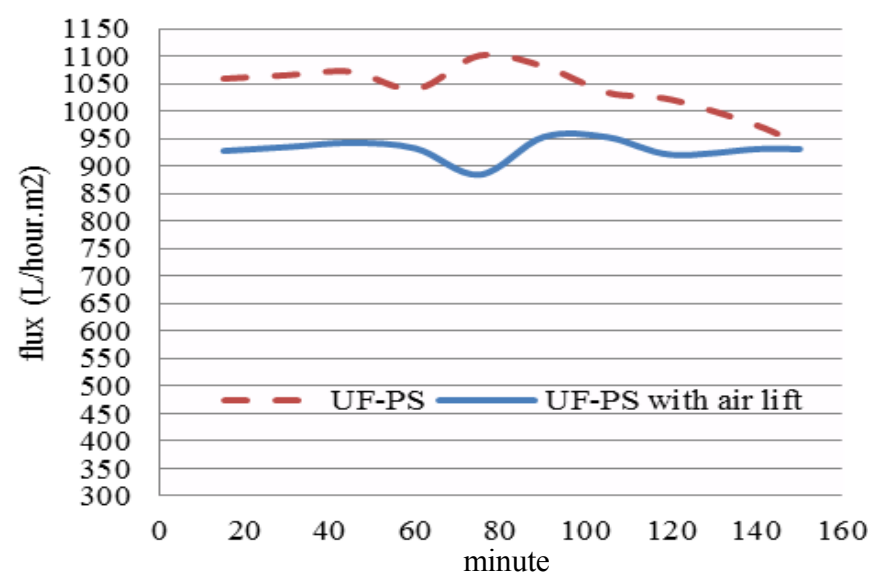

Fig. 5 Membrane flux of UF-PS membrane pretreatment.

without air lift system is less than 3 hours. Although in the application of UF-PS with air lift system showed flux lower than UF operation without air lift system but longer filtration cycle was achieved. Stable flux and operation pressure were achieved longer because scouring of membrane surface by air and avoidance of particulate deposition in membrane surface effectively. Longer filtration cycle with air lift system could 
produce much clean water and also could save clean water for membrane backwash demand. For energy demand reduction, air injection in the feed of UF membrane was intermittently applied.

Recommended UF membrane maintenance procedure was followed to operate UF as pretreatment in optimal way. Potential particulate deposition or clogging creation by cake filtration deposits in the membrane surface is removed with backwash flow and air scouring which is provided by air injection located at the bottom of the module. Air scouring improves the backwash efficiency and reduces the permeate water consumption. The interval between two chemical cleaning is increased too. Backwash is periodically performed with clean water (from the filtrated tank) after observed flux decreased or UF operation pressure showed more than 2 bars. Typically, duration of backwash of UF membrane operation with air lift system is 10-15 minutes. At operation backwash of UF membrane without air lift system spent longer duration backwash three to five times than operation membrane with air lift system. The physical parameters such as turbidity, $\mathrm{pH}$ and temperature in the retentate flow were observed during backwash. While backwash chemically done depend on decreased membrane flux and observed irreversible fouling. In the case of decreased flux more than $50 \%$, chemically cleaning applied to the membrane using circulation water with $5 \mathrm{~L}$ of GW 110 solution at cleaning process of $\mathrm{pH}$ of 2 and $1 \mathrm{~L}$ of $\mathrm{MC} 112$ solution at cleaning process of $\mathrm{pH}$ of 12 . During this research, chemically cleaning of UF membrane was done once at two tested UF. After chemical cleaning, the UF membrane flux became decrease about $5 \%$ than initial flux.

Figure 6 shows the result of UF-PP filtration on turbidity with values higher than the result of UF-PS filtration. Thus in this pilot experiment, the use of addition filtration after UF-PP operation with activated carbon filtration is required before entering the $\mathrm{RO}$ membranes. It was observed the quality of pretreatment produced turbidity permeate about 2 NTU. While the quality of the pretreatment of UF-PS showed better results in the filtration of turbidity and color than UF-PP pretreatment, especially operation with air lift system.

\section{Membrane RO performance}

Membrane RO - low pressure which was operated at 5 and 8 bars of pressure, showing the characteristic flux as in Figs 7-8. The tendency of rapid RO flux decline did not occur on the pressure applied, and there is little difference in processing water from permeates of UFPP or UF-PS operation. UF membrane pretreatment, greatly affect in preventing fouling that can increase the osmotic pressure at the surface of RO membrane.

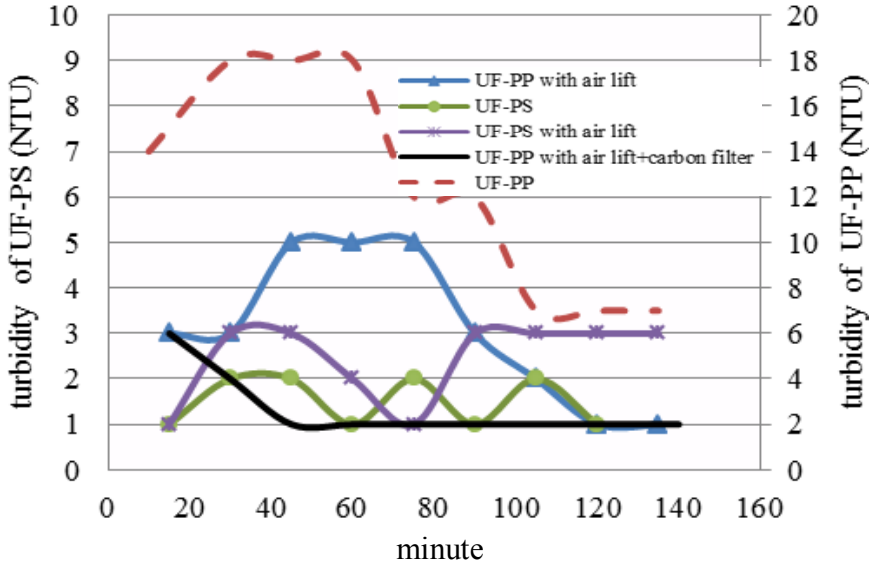

Fig. 6 Permeate quality of UF-PP and UF-PS membrane pretreatment.

Through higher quality of permeate from UF pretreatment also could prolong RO membrane life with reduces chemical cleaning demand. However potential highly fouling of surface brackish water should be always concerned at membrane pretreatment.

The ability of TDS rejection by RO after UF-PS membrane is better than UF-PP membrane, as well as for color rejection, as shown at Table 2 . The turbidity of RO permeate is less than 1 NTU for pretreatment by UF-PS but higher turbidity on RO permeate achieved as a result of UF-PP pretreatment. The other parameters such as TDS, color or salinity have also better rejection in the operation of RO by UF-PS than UF-PP pretreatment. But permeate quality of RO operation by UF-PP pretreatment shows better iron rejection than UF-PS pretreatment. Continuous good permeate quality from pretreatment stage ensures an optimum operation of RO membranes. RO membrane fouling could be major limitation for surface brackish water with high turbidity.

Table 2. Rejection percentage of RO membrane with UF membranes pretreatment

\begin{tabular}{lrrrr}
\hline Parameters & $\begin{array}{c}\text { UF-PP } \\
+ \text { RO } \\
\text { (5 bars) }\end{array}$ & $\begin{array}{c}\text { UF-PP }+ \\
\text { RO } \\
\text { (8 bars })\end{array}$ & $\begin{array}{c}\text { UF-PS } \\
+ \text { RO } \\
\text { (5 bars) }\end{array}$ & $\begin{array}{c}\text { UF-PS } \\
+ \text { RO } \\
\text { (8 bars })\end{array}$ \\
\hline $\begin{array}{l}\text { TDS } \\
\text { (mg/L) }\end{array}$ & 96.81 & 96.84 & 98.41 & 98.54 \\
$\begin{array}{l}\text { Turbidity } \\
\text { (NTU) }\end{array}$ & 99.00 & 100.00 & 100.00 & 100.00 \\
$\begin{array}{l}\text { Color } \\
\text { (PtCo) }\end{array}$ & 99.55 & 99.87 & 100.00 & 100.00 \\
$\begin{array}{l}\text { Chloride } \\
\text { (mg/L) }\end{array}$ & 95.47 & 95.47 & 97.74 & 93.26 \\
$\begin{array}{l}\text { Salinity } \\
\text { (mg/L) }\end{array}$ & 84.42 & 85.71 & 86.52 & 93.26 \\
$\begin{array}{l}\text { Iron } \\
\text { (mg/L) }\end{array}$ & 93.91 & 96.95 & 84.51 & 91.55 \\
\hline
\end{tabular}




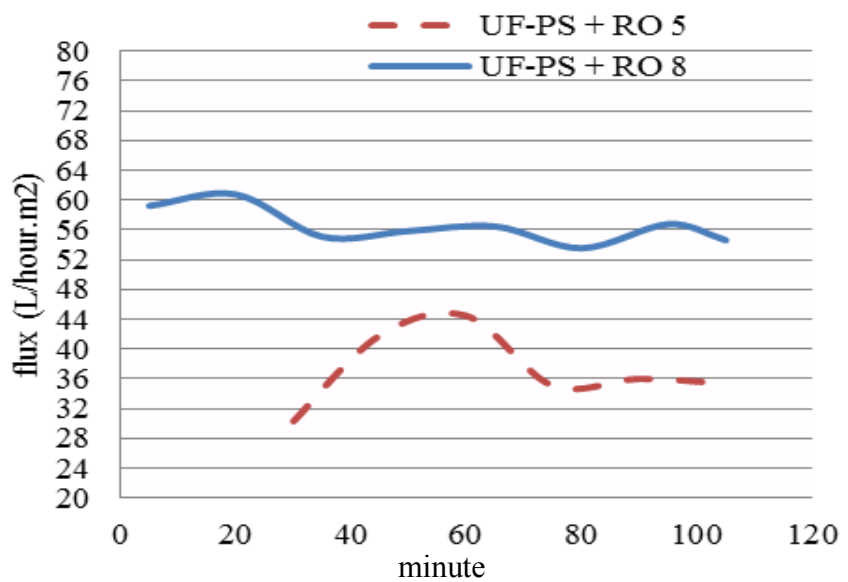

Fig. 7 Flux of RO membrane with UF-PS pretreatment.

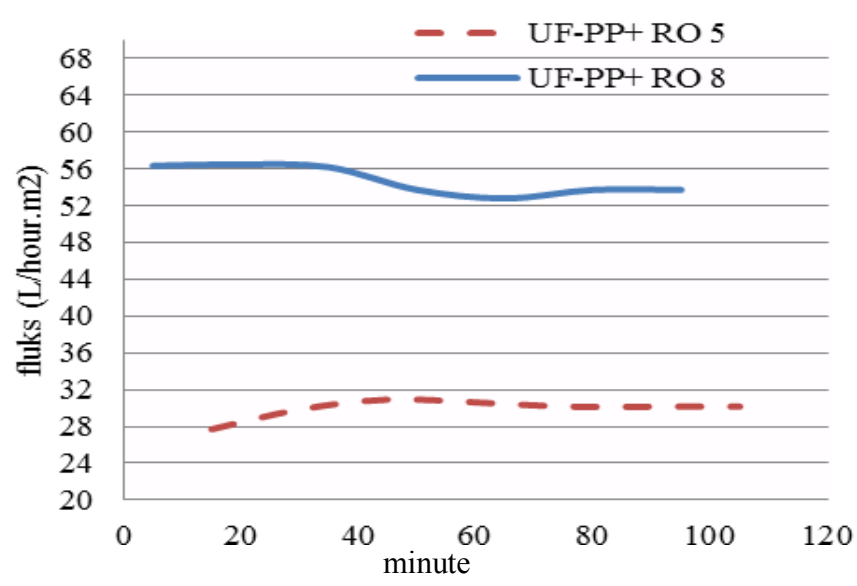

Fig. 8 Flux of RO membrane with UF-PP pretreatment.

RO membrane hydraulic performance tends to increase with UF-PS pretreatment (Fig. 7), while operation with UF-PP pretreatment resulted lower flux both at pressure of 5 and 8 bars, as shown at Fig. 8. It was achieved a stabilized flux of about $56 \mathrm{~L} /$ hour $\cdot \mathrm{m}^{2}$ at UF-PS pretreatment and $53 \mathrm{~L} /$ hour $^{2} \mathrm{~m}^{2}$ at UF-PP pretreatment. Therefore, configuration of UF-PS membrane module as RO pretreatment has ability better than UF-PP, both good permeate quality and higher flux. In general, application of UF-PS with air lift system could be cost effective. It is expected chemical cleaning frequency and membrane replacement are reduced.

\section{CONCLUSION}

The major challenge of water infrastructure in coastal areas is to perform a reliable treatment of the feed water in which water has been categorized as brackish water. The source and chemical composition of brackish waters varies greatly and depend on coastal location, usually has a complex content of salt, colloidal and suspended solids or organic compounds. Appropriate treatment need to be conducted based on water constituent to be removed or local condition. Membrane technology could be the choice to provide drinking water from surface or ground water intruded by seawater or contaminated by waste. A consideration in increasing Ultrafiltration (UF) and Reverse Osmosis (RO) membrane performance in treating brackish water and extend lifespan of the membranes could apply Ultrafiltration-Polysulfone (UF-PS) membrane for pretreatment of RO membrane as concern for colloidal and suspended constituent removal. To prevent or minimize fouling, scaling or membrane plugging, the air lift system in the feed of the UF membrane module could support high stabilized flux and feed pressure requirements. However human resources barrier also has to be considered, because membrane technology for water treatment applications is quite new in some coastal areas and require proper training. In general, the suitability of membrane technology with UF membrane operated by air lift system and RO membrane-low pressure could accepted as condition of brackish water source in Indonesia's coastal areas in producing potable water.

\section{REFERENCES}

Alley, R.E. (2007) Water Quality Handbook, $2^{\text {nd }}$ Ed. New York: Mc Graw Hill.

Cheremisinoff, P.N. (2002) Handbook of Water and Wastewater Technologies, Butterworth-Heinemann.

Cui, F.Z., Bellara, R.S. \& Homewood, P. (1997) Airlift crossflow membrane filtration - a feasibility study with dextran ultrafiltration, Journal of Membrane Science, 128(1), 83-91. doi: 10.1016/S0376-7388(96)00280-3

Heran, M., Durante, F., Lebegue, J. \& Gramick, A. (2006), Air lift relevance in a side stream MBR system, Desalination, 199(1), 485-486. 10.1016/j.desal.2006.03.198

Lorain, O., Hersant, B., Persin F., Grasmick, A., Brunard, N. \& Espenana, M.J. (2007) Ultrafiltration membrane pre-treatment benefits for Reverse Osmosis process in seawater desalting. Quantification in terms of capital investment cost and operating cost reduction, Desalination, 203(3), 277-285. doi: 10.1016/j.desal.2006.02.022

Ministry of Public Works (2010) Indonesia Water SupplyInfrastructure PPP investment opportunities.

Pearce, K.G. (2008) UF/MF pre-treatment to RO in seawater and wastewater reuse applications: a comparison of energy costs, Desalination, 222(1), 66-73. doi: 10.1016/j.desal.2007.05.029

Rahman, A. (2010) Sea Level Rise and Its Impact to on the Coastal Areas in Jakarta Metropolitan City, Proceedings Of Workshop Increasing Capacity of Local Scientists for Climate Change Impact \& Vulnerability Assessment on Indonesia Archipelago, Bogor Agricultural University and Asia Pacific Network for Global Change Research (Apn).

Rautenbach, R. \& Albert, R. (1989) Membrane Process, New York: John Willey \& Son Ltd.

Rudiastuti, W.Aninda, Arhatin, Endryani, Risti, Gaol, and Lumban, Jonson. (2010) Assessment of coastal inundation in selected coastal areas of Indramayu due to sea level rise, Proceedings of Workshop Increasing Capacity of Local Scientists for Climate 
Change Impact \& Vulnerability Assessment on Indonesia Archipelago, Bogor Agricultural University and Asia Pacific Network for Global Change Research (Apn).
Szép, A., Horváth, Z.H., Véha, A. \& Hodúr, C. (2009) Estimate the cost of water treatment technologies, 4th Aspects and Visions of Applied Economics and Informatics, March 26 - 27, Debrecen, Hungary. 